\title{
The Evaluation Model of Transaction Trust in online Group-buying Based on Transaction History Information
}

\author{
Yan Zou, Weijie Chen*, Shan Li, Yiyang Si \\ school of economics and management, Chongqing Normal UniversityChongqing, R.P. China \\ chwj721@163.com
}

Keywords: online group-buying; transaction amounts; transaction dates; transaction trust; transaction risk

\begin{abstract}
Trust is an vital factor affecting online transaction. This paper presents an evaluation model of transaction trust based on transaction history information including past transaction amounts, transaction dates and rates of favorable comments, which can widen the applicability of the trust evaluation model. Some case studies are given to testify the effectiveness of the evaluation model presented in this paper. The results mainly show that (1) the new transaction with positive category difference of transaction amounts will have higher transaction risk than that with negative category difference of transaction amounts;(2) the bigger the absolute value of category difference of transaction amounts is, the higher the transaction risk is;(3)the farther the transaction date of the past transaction is from the new transaction, the smaller the impact on the risk of the new transaction is.
\end{abstract}

\section{Introduction}

Online group-buying mechanisms are being widely used for both business-to-business (B2B) and business-to-consumer (B2C) transactions. As a new way of consumption, online group-buying refers that a certain number of consumers buy the same goods at a certain discount through the Internet. Its basic feature lies in gathering money through the cohesive force of Internet, which can increase negotiation force of customers and make customers get a preferential transaction price. The organizers of online group-buying mainly include consumers themselves, sellers and professional purchasing associations. Group-buying websites have been developed rapidly in recent years, however, by the end of 2014, the failing rate of group-buying websites has reached to $90 \%$. Thus online group-buying faces enormous risks with the rapid development. For customers, before deciding to joining group-buying, they need to know the transaction risk and then make purchase decisions. So the evaluation of transaction trust and risk is particularly necessary for online groupbuying.

Due to the particularity of group-buying transactions, the measurement of trust and risk has attracted wide attention from scholars. Researchers have presented some classic evaluation models of trust, such as Beth trust management model ${ }^{[1]}$, subjective logic trust model ${ }^{[2]}$. M. H. Hsu et al. presented a theoretical model to examine the antecedents of repurchase intention in online groupbuying by integrating the D\&M model and trust literature ${ }^{[3]}$. The trust-based whole process ecommerce credit risk management model was proposed in [4] to enhance the trust between the sellers and buyers. In the next year, a coherent adaptive trust model for quantifying and comparing the trustworthiness of group-buying websites based on a transaction-based feedback system and social network are discussed in [5].Trust is an vital factor affecting online transaction. Many factors can improve the trust of consumers to the sellers including scale of websites, reputation, customer satisfaction, product return and refund policy, and consumer's shopping experience ${ }^{[6]}$. Y. Wang and V. Varadarajan ${ }^{[7]}$ proposed several trust metrics for the trust evaluation and pointed out that a constant good reputation leads to a series of good trust values. W. L. Shiau and M. M. Luo ${ }^{[8]}$ demonstrated that reciprocity, trust, satisfaction, and seller creativity provide considerable explanatory power for intention to engage in online group buying behavior. Z. Zhang and $\mathrm{C}$. $\mathrm{Gu}^{[9]}$ indicated that social interaction has significant and normative influences on consumer trust by an 
empirical study of online group-buying. The results from researches ${ }^{[10]}$ indicate that perceived usefulness, perceived ease of use and perceived risk all have a significant relationship with consumer attitudes. Some researchers focused on the relations between new transaction and existing transactions. R. J. Kauffman and B. Wang pointed that the number of existing orders has a significant positive effect on new orders placed during each three-hour period, indicating the presence of a positive participation externality effect ${ }^{[11]}$. However, in most existing trust evaluation models, past transaction conditions and transaction history are usually ignored, so this paper introduces some characters of past transactions into the trust evaluation model of online groupbuying.

To facilitate our discussion, we first present the correlative assumptions and definitions in Section 2.In section 3 an evaluation model of trust for online group-buying transactions based on transaction amounts is firstly presented in detail, then we extend the model by considering more factors, such as the transaction date and the rate of favorable comments. Some study cases are given to illuminating the effectiveness of our evaluation model in Section 4 . At last, we conclude the paper with a summary and give some suggestions to reduce transaction risk in last section.

\section{Preliminaries}

For any new transaction between consumers and group-buying websites, assuming that the relative data of past transactions is public. So we consider that the difference between the old transaction amount and the new transaction amount is one of the important impact factors for evaluating transaction trust.

Firstly, let $\Delta_{a}=$ cash $_{\text {new }}-$ cash $_{\text {old }}$ be the difference between the old transaction amount and the new transaction amount, where cash $_{\text {new }}$ and cash $_{\text {old }}$ are the amount of the new transaction and the amount of the old transaction, respectively. Let $\theta_{a}$ be the impact factor of $\Delta_{a}$ which shows how $\Delta_{a}$ influences the trust of the new transaction, and $0<\theta_{a}<1$. When $\Delta_{a}=0$, we have $\theta_{a}=1$, which means an old transaction having the same transaction amount with the new transaction has a maximum influence on the new transaction. When $\Delta_{a} \neq 0$, we have $0<\theta_{a}<1$.

Next, we consider two cases: $\Delta_{a}>0$ and $\Delta_{a}<0$. Considering the exponential function can reflect the property of $\theta_{a}$ pretty well, we define $\theta_{a}$ as

$$
\theta_{a}=1 /\left(\rho e^{\Delta_{a}^{*} \alpha}+(1-\rho) e^{-\Delta_{a}^{*} \alpha}\right) \quad \text { if } \Delta_{a} \geq 0,
$$

where $\alpha \in(0,1]$ is the decay factor, $\rho \in[0.5,1)$ is the control factor which controls the impact of $\Delta_{a}$ with difference on the impact factor $\theta_{a}$. The larger $\rho$ is, the less the impact is.

Definition 1. Let cash $_{\text {new }}$ be the amount of the new transaction and cash $_{\text {old }}$ be the amount of the old transaction. Then the impact factor $\theta_{a}$ is defined as

$$
\theta_{a}= \begin{cases}\frac{1}{\rho e^{\Delta_{a}^{*} \alpha}+(1-\rho) e^{-\Delta_{a}^{*} \alpha}} & \text { if } \Delta_{a} \geq 0, \\ \frac{1}{\rho e^{\Delta_{a}^{*} \alpha}+(1-\rho) e^{-\Delta_{a}^{*} \alpha}} \cdot(1-\beta)+\beta & \text { if } \Delta_{a}<0\end{cases}
$$

where $\Delta_{a}=$ cash $_{\text {new }}-$ cash $_{\text {old }}, \alpha \in(0,1], \rho \in[0.5,1)$ and $\beta \in(0,1)$.

In fact, for simplifying the computation, we can use the difference between the category of cash $_{\text {new }}$ and the category of cash $_{\text {old }}$ instead of detailed amounts. Here we can define a classification function of transaction amounts as follows.

Definition 2. Let cash be the transaction amount of a transaction, so a classification function of transaction amounts is defined as 


$$
\operatorname{ca}(\text { cash })=\left\{\begin{array}{ll}
1 & \text { if } \operatorname{cash} \in[1,100] \\
2 & \text { if } \operatorname{cash} \in[101,500] \\
3 & \text { if } \text { cash } \in[500,2000] \\
\cdots . . . & \\
9 & \text { if } \operatorname{cash} \in[100001,200000] \\
10 & \text { if } \operatorname{cash} \in[200001,+\infty)
\end{array},\right.
$$

Given a transaction amount, we can compute the category of the transaction amount. For example, if $\operatorname{cash}=1000$, then $c a(1000)=3$.

According to Definition 2, the $\Delta_{a}$ in Eq.(3) can be replaced with $\Delta_{a}$ where $\Delta_{c}=c a\left(\operatorname{cash}_{n e w}\right)-c a\left(\right.$ cash $\left._{\text {old }}\right)$. Of course, the classification function of transaction amounts in different industries should be different. So, we need to define different classification functions for different industries.

\section{The Trust Evaluation Model in online group-buying}

\subsection{The Fundamental Model}

Definition 3. Assume a set of trust values $T=\{T, T, \ldots, T\}$ from a past transactions set Purchase $=\left\{P_{l}, P_{2}, \ldots, P_{n}\right\}$ is known, then the trust value of the new transaction is:

$$
T_{\text {new }}=\frac{1}{n} \sum_{i=1}^{n}\left(\theta_{c}(i) \cdot T_{i}\right) \text {, }
$$

where $T_{i} \in[0,1]$ is the trust value of the old transaction $P_{i} . T_{i}=0$ means the trust value of this transaction is very poor, while $T_{i}=1$ means the trust value is very high, and $\theta_{c}(i)$ is the impact factor of $\Delta_{c}(i), \Delta_{c}=c a\left(\operatorname{cash}_{\text {new }}\right)-c a\left(\operatorname{cash}_{\text {old }}(i)\right)$ where $\operatorname{cash}_{\text {old }}(i)$ is the transaction amount of the old transaction $P_{i}$. So, according to the above definitions, we define the transaction risk of a new transaction.

Definition 4. If the trust value of the new transaction lunched by group-buying websites is $T_{\text {new }}$, the transaction risk of a new transaction is defined as $R_{\text {new }}=1-T_{\text {new }}$.

So if customers know relative past transaction data before the new transaction begins, they can compute the risk value of the new transaction, which can provide the reference for customers to make purchase decisions.

\subsection{The Extended Model Considering Transaction Dates of Past Transactions}

In fact, different transaction dates of past transactions have different influences on the new transaction. To evaluate the trust of the new transaction more accurately, different weights should be assigned to past transactions taking place in disparate periods. We consider that a past transaction closing to the new one should get a bigger weight. Therefore, transaction dates of those past transactions are considered in the evaluation model.

Definition 5. Considering transaction dates of past transactions, the trust value of a new transaction is defined as $T_{n e w}=\sum_{k=1}^{l}\left(w^{k} T_{p}^{k}\right),(7)$

where (1) $l$ is the number of periods we assign for all past transactions. (2) $w^{(k)}$ is the timeweight of a past transaction taking place in the period $t_{k}(k=1,2, \ldots, l-1)$ and the smaller $k$ is, the farther the transaction date of the past transaction is from the date of the new transaction. So we have $w^{(k)} \leq w^{(k+1)}$ and $\sum w^{(k)}=1$. (3) $T_{p}^{(k)}=\left(\sum_{j=1}^{m^{(k)}}\left(\theta_{c}^{(k)}(j) \cdot T_{j}^{(k)}\right)\right) / m^{(k)}$ is the transaction trust value during the period $t_{k}, m^{(k)}$ is the number of transactions taking place in period $t_{k}$, and $T^{(k)}$ is the trust value of the past transaction with the transaction amount $\operatorname{cash}_{\text {od }}^{(k)}(j)$ taking place in the period $t_{k} .(4)$ 
$\theta_{c}^{(k)}(j)$ is the impact factor of amounts category resulting from $\Delta_{c}^{(k)}(j)=c a\left(\operatorname{cash}_{n e w}\right)-\operatorname{ca}\left(\operatorname{cash}_{\text {old }}^{(k)}(j)\right)$, where $\operatorname{cash}_{\text {old }}^{(k)}(j)$ is the transaction amount of the $k$ th transaction in period $t_{k}$.

Specially, we build a simple weight distribution function to assign weights for past transactions. Given parameters $\lambda(0.5<\lambda<1)$ and $\mu \in\{1,2,3, \ldots\}$, the weight of period $t_{k}$ can be computed by

$$
w^{(k)}=v^{(k)} / \sum_{i=1}^{l} v^{(i)}, \text { where } v^{(k)}=1-e^{-\lambda^{2} \cdot(1 / \mu)}, 0.5<\lambda<1, \mu \in\{1,2,3, \ldots . .\} .
$$

For example, let $l=10, \lambda=0.7$ and $\mu=2$, we have

$W=\{0.0598,0.0771,0.0882,0.0964,0.1027,0.1078,0.1121,0.1157,0.1188,0.1215\}$.

\subsection{The Extended Model Considering the rate of favorable comments}

In this section, the rate of favorable comments will be introduced into the evaluation model of trust.Let $F_{j}^{(k)}$ be the rate of favorable comments for a past transaction with the amount transaction $\operatorname{cash}_{\alpha d}^{(k)}(j)$ taking place in the period $t_{k}$, then the trust value of the new transaction is defined as $T_{\text {nev }}=\sum_{k=1}^{l}\left(w^{(k)} \cdot T_{F}^{(k)}\right)$, Where $T_{F}^{(k)}=\left(\sum_{j=1}^{m^{(k)}}\left(\theta_{i}^{(k)}(j) \cdot F_{j}^{(k)} \cdot T_{j}^{(k)}\right)\right) / m^{(k)}$ is the revised transaction trust value of the period $t_{k}$.

\section{Case Studies}

\subsection{Case 1}

Specific statistical data are listed in Table I where the unit of transaction amount $\operatorname{cash}_{\text {old }}^{(k)}(j)$ is ten thousand Chinese yuan. From Table 1, we know that there are 13 past transactions in total, where two transactions taking place in period $t_{1}$ and three transactions took place in period $t_{4}$. Therefore, $k=10, m^{(1)}=2, m^{(4)}=3$ and $m^{(k)}=1(k=2,3,5,6,7,8,9,10)$. Assuming cash $_{\text {new }}=3, \alpha=0.5, \rho=0.5$, $\beta=0.85, \lambda=0.7, \mu=2$, we can get the results listed in Table $\Pi$.

Table I. The statistical data of past transactions

\begin{tabular}{cccccccccccccc}
\hline$k$ & 1 & 1 & 2 & 3 & 4 & 4 & 4 & 5 & 6 & 7 & 8 & 9 & 10 \\
\hline cash $_{\text {odd }}^{(k)}(j)$ & 1 & 1.2 & 1.5 & 1.3 & 2 & 1.5 & 1.6 & 3 & 2 & 4 & 1.9 & 5 & 1.2 \\
$T_{j}^{(k)}$ & 0.85 & 0.83 & 0.74 & 0.80 & 0.69 & 0.77 & 0.90 & 0.81 & 0.78 & 0.77 & 0.63 & 0.50 & 0.91 \\
$F_{j}^{(a)}$ & 0.81 & 0.83 & 0.86 & 0.82 & 0.89 & 0.76 & 0.61 & 0.87 & 0.93 & 0.90 & 0.88 & 0.83 & 0.78 \\
\hline
\end{tabular}

Table II. The statistical results

\begin{tabular}{ccccccccccc}
\hline$k$ & 1 & 2 & 3 & 4 & 5 & 6 & 7 & 8 & 9 & 10 \\
\hline$w^{(k)}$ & 0.0598 & 0.0771 & 0.0882 & 0.0964 & 0.1027 & 0.1078 & 0.1121 & 0.1157 & 0.1188 & 0.1215 \\
$T_{F}^{(k)}$ & 0.4518 & 0.5644 & 0.6448 & 0.4499 & 0.7047 & 0.6433 & 0.6930 & 0.4916 & 0.3931 & 0.6977 \\
\hline
\end{tabular}

So we can get $T_{\text {new }}=0.5785$ and $r_{\text {new }}=1-T_{\text {new }}=0.4215$. These results can give customers a reference to make purchase decisions.

\subsection{Case 2}

Now assuming that there are only two transactions. We only consider how the latest transaction effect the new transaction, then $k=1, m^{(1)}=1$. Let the new transaction amount be 4 thousand Chinese yuan, and the parameters $\alpha, \rho, \beta, \lambda, \mu$ are the same as case 1 . 
Table III. The statistical results of case 2

\begin{tabular}{ccccccc}
\hline Type & casshosd $_{\phi_{d \alpha}(j)}$ & $T_{j}^{(k)}$ & $F_{j}^{(k)}$ & $w^{(k)}$ & $\theta_{c}^{(k)}(j)$ & $T_{F}^{(k)}$ \\
\hline 1 & 0.4 & 0.87 & 0.91 & 1 & 0.4251 & 0.3587 \\
2 & 3 & 0.88 & 0.92 & 1 & 1 & 0.8096 \\
3 & 30 & 0.86 & 0.91 & 1 & 0.9138 & 0.7151 \\
\hline
\end{tabular}

In Table III, Type 1 means the transaction amount of the past transaction is less than the new one, Type 2 means the transaction amount of the past transaction is roughly equal to the new one, and Type 3 means the transaction amount of the past transaction is extremely larger than the new one. Therefore, we can compute the trust and trust risk of three different types. The results are listed in Table 4.

Table IV. The trust and trust risk of three different types

\begin{tabular}{ccc}
\hline Type & $T_{\text {new }}$ & $r_{\text {new }}$ \\
\hline 1 & 0.3587 & 0.6413 \\
2 & 0.8096 & 0.1904 \\
3 & 0.7151 & 0.2849 \\
\hline
\end{tabular}

According to Table IV, if there is little difference between the amount of the past transaction and the new transaction, the trust risk of the new transaction will be very low .So when launching a new transaction, the group-buying website should not change the transaction amount rashly.

\subsection{Case 3}

This case discusses how the positive category difference of transaction amounts influence on the transaction trust and risk. The parameters values of $\alpha, \rho, \beta, \lambda, \mu$ are the same as case 1 . In addition, let $k=1, T=0.88$ and $F=0.92$ for each transaction. Results are listed in Table V.

\begin{tabular}{ccccccc} 
Table V. & \multicolumn{6}{c}{ Influences of the positive category difference } \\
\hline$\Delta_{c}^{(i)}(j)$ & 0 & 1 & 3 & 5 & 7 & 9 \\
\hline$T_{\text {new }}$ & 0.8096 & 0.7180 & 0.3442 & 0.1320 & 0.0488 & 0.0180 \\
$r_{\text {new }}$ & 0.1904 & 0.2820 & 0.6558 & 0.8680 & 0.9512 & 0.9820 \\
\hline
\end{tabular}

From Table V, we know that the bigger the fluctuation scope of transaction amounts between the new transaction and its last transaction, the higher the transaction risk is, and the lower purchase intention of customers are. So if group-buying websites want to make deals, one of feasible methods is to add transactions amounts incrementally, which make the transaction risk value quite small, and the customer is likely to purchase goods.

\section{Conclusions}

In this paper, we present the evaluation model of risk based on transaction amounts, transaction dates and rates of favorable comments of those past transactions, and some case studies are given to demonstrate the validness of the evaluation model. The data the evaluation model needed are easy to get, and the evaluation model can be performed in each type of group-buying websites. However, the evaluation model only considered three notable factors. In future work, more factors, such as risk preference of customers, the social relationship between customers, can be considered to make the model universal in the practical application.

According to the trust evaluation model and case studies, we can see that the trust of the new transaction is related to category difference of transaction amounts, transaction dates and rates of favorable comments of those past transactions. If group-buying websites want to shows a good reputation for customers, in addition to deal honestly, they can also take necessary measures. For example, don not change the amount of transaction suddenly. If it is necessary, change gradually. Be sure to trade honestly and provide high quality products and services to customers for gaining a high rate of favorable comments. Be sure to provide complete and true past transaction information to customers to help them to make purchase decisions. 


\section{Acknowledgment}

Our work gets support from Science Foundation of Ministry of Education of China(13YJC630252), the Fund of Science and Technology Project of Education Department of Chongqing, China(KJ1400533) and the fund of Social Science Planning Project of Chongqing, China(2014BS113). The authors declared that they had no conflicts of interest to this work.

\section{References}

[1] T. Beth, M. Borcherding, B. Klein. 1994. Valuation of trust in open networks, Springer Berlin Heidelberg.

[2] A. Josang. Trust-based decision making for electronic transactions. 1999. Proceedings of the Fourth Nordic Workshop on Secure Computer Systems (NORDSEC'99):496-502.

[3] M. H. Hsu, C. M. Chang, K. K. Chu, et al. 2014. Determinants of repurchase intention in online group-buying: The perspectives of DeLone \& McLean IS success model and trust, Computers in Human Behavior,36:234245.

[4] D.Yuan, T. Lu, X. Yang, \& L. Yan. 2010. A theory analysis and model research on e-commerce credit risk management, E-Business and E-Government (ICEE), 2010 International Conference on IEEE:2006-2009.

[5] X. Liu, Y. Tian, W. Wang, \&Y. Cui. 2011. A social network-based trust model for group-buying, Broadband Network and Multimedia Technology (IC-BNMT), 2011 4th IEEE International Conference: 385-389.

[6] S. L. Jarvenpaa, N. Tractinsky, L. Saarinen. 1999. Consumer Trust in an Internet Store: A Cross - Cultural Validation, Journal of Computer - Mediated Communication, 2(5):1-8.

[7] Y. Wang, V. Varadarajan. 2004. Interaction trust evaluation in decentralized environments, E-Commerce and Web Technologies, Springer Berlin Heidelberg:144-153.

[8] W. L. Shiau, M. M. Luo.2012. Factors affecting online group buying intention and satisfaction: A social exchange theory perspective, Computers in Human Behavior, 28(6): 2431-2444.

[9] Z. Zhang, C. Gu. 2015. Effects of Consumer Social Interaction on Trust in Online Group-Buying Contexts: An Empirical Study in China, Journal of Electronic Commerce Research, 6(1): 1-8.

[10] W. M. Lim, D. H.Ting. 2014. Consumer acceptance and continuance of online group buying, Journal of Computer Information Systems, 54(3):87-96.

[11] R. J. Kauffman, B. Wang.2001. New buyers' arrival under dynamic pricing market microstructure: The case of group-buying discounts on the Internet, Journal of Management Information Systems, 2001, 18(2): 157-188. 